\title{
Haplophyllum linifolium (L.) G. Don fil: EAEn arriskuan dagoen landarearen kontserbazioa.
}

\section{Conservation of Haplophyllum linifolium (L.) G. Don fil: an endangered species of the Basque Country.}

Asier Jáñez ${ }^{1}$, Agustí Agut ${ }^{1}$, José Ignacio García-Plazaola²

Laburpena

Haplophyllum linifolium (L.) G. Don fil. Iberiar Penintsulako endemismoa da, Euskal Autonomia Erkidegoko flora mehatxatuaren zerrendan galtzeko arriskuan bezala katalogatzen dena. Ikerketa honen helburuak izan dira, batetik espezie honen hozidura protokoloak lortzea eta, bestetik, espezie horren hazien bideragarritasuna ikustea Tetrazolio Testaren bitartez. Horiek egitea ezinbestekoa zen espezie honen ex situ kontserbaziorako, baita landarearen hazkuntza egiteko ere etorkizunean in situ kontserbazio ekintzak egiteko, kasurako populazio indarketak. Alde batetik, lortutako hazien bideragarritasuna \%64koa izan zen. Bestalde, hozidura protokolo egokienak zehaztu ziren, emaitzen analisi estatistikoa eginez R softwarearen bitartez, erregresio binomial logistikoaren ereduan oinarrituz. Lortutako hozidurak \%43 eta \%45 bitartekoak izan ziren, estratifikazio hotza $\left(4^{\circ} \mathrm{C}, 60\right.$ egun) egin ondoren, ikasitako lau baldintzetan: $15^{\circ} \mathrm{C}, 2^{\circ} \mathrm{C}$, $20 / 10^{\circ} \mathrm{C}$ eta $25^{\circ} \mathrm{C}, 12 / 12$ ordu argi/iluntasun fotoperiodoekin.

Gako hitzak: ex situ, hozidura protokoloak, bideragarritasuna, erregresio binomial logistikoa.

1 1Olarizuko Lorategi Botanikoko Germoplasma Bankua.

Dpto. de Medio Ambiente y Salud Pública del Ayuntamiento de Vitoria-Gasteiz.

Casa de la Dehesa de Olárizu s/n. 01006. Vitoria-Gasteiz (Álava/Araba). País Vasco.

España.

*Correspondencia: ajplanez@gmail.com; aagut@vitoria-gasteiz.org

2 Landareen Biologia eta Ekologia.

Zientzia eta Teknologia Fakultatea/Facultad de Ciencia y Tecnología.

Euskal Herriko Unibertsitatea/Universidad del País Vasco (UPV/EHU).

Barrio Sarriena s/n. 48940 Leioa (Bizkaia). País Vasco. España. 


\title{
Resumen
}

Haplophyllum linifolium (L.) G. Don fil es un endemismo de la Península Ibérica, catalogado como especie en Peligro de Extinción en el catálogo de especies amenazadas de la Comunidad Autónoma del País Vasco. Los objetivos de este estudio fueron obtener los protocolos de germinación y establecer la viabilidad de las semillas de esta especie a través del Test de Tetrazolio. Estas acciones son imprescindibles para la conservación ex situ de la especie, así como para llevar a cabo la producción de planta para futuras acciones con la que realizar acciones de conservación in situ, como refuerzos poblacionales. Por un lado, los porcentajes de viabilidad obtenidos fueron del 64\%. Por otro lado, se establecieron los protocolos óptimos de germinación realizando el análisis estadístico de los resultados, basado en el modelo de regresión binomial logística, mediante el software R. Los porcentajes de germinación obtenidos oscilaron entre $43 \%$ y $45 \%$, a las cuatro condiciones de ensayo estudiadas $\left(15^{\circ} \mathrm{C}, 20^{\circ} \mathrm{C}, 20 / 10^{\circ} \mathrm{C}\right.$ y $25^{\circ} \mathrm{C}$, con fotoperíodo 12/12 horas luz/oscuridad), previa realización de una estratificación fría como pretratamiento $\left(4^{\circ} \mathrm{C}, 60\right.$ días $)$.

Palabras clave: Ex situ, protocolo de germinación, viabilidad, regresión binomial logística.

\begin{abstract}
Haplophyllumlinifolium (L.) G. Don fil is an endemism of Iberian Peninsula, cataloged as endangered species in the threatened species catalog of the Autonomous Community of the Basque Country. The aims of this study were to obtain the germination protocols and establish the viability of the seeds of this species through Tetrazolium test. These actions are essential for ex situconservation of species, as well as to carry out the production of plant for future in situ actions, like population reinforcements.

On the one hand, the viability percentages obtained were $64 \%$. On the other hand, the optimal germination protocols were established making the statistical analysis of the results, based on the binomial logistic regression model, using software $R$.

The germination percentages obtained ranged from $43 \%$ to $45 \%$ at studied four test conditions $\left(15^{\circ} \mathrm{C}, 20^{\circ} \mathrm{C}, 20 / 10^{\circ} \mathrm{C}\right.$ and $25^{\circ} \mathrm{C}$, with $12 / 12$ hour light/darkness photoperiod), following a cold pre-treatment $\left(4^{\circ} \mathrm{C}, 60\right.$ days).
\end{abstract}

Key words: Ex situ, germination protocol, viability, binomial logistic regression.

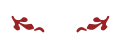

\section{Sarrera}

Azken urteetan landare biodibertsitatea abiadura handian gutxitzen ari da, Iberiar PenintsuIan nahiz mundu mailan (Bañares et al., 2010; Phartyal et al., 2002). Galera hori saihesteko biderik onena zera da, espezieen kontserbazioaren habitata babestea, hau da, in situ kontserbazioa. Beraz, ezinbestekoa da ex situ tresnak edukitzea, hots, habitat naturaletik kanpo, mehatxu egoeretan, landare-espezieen kontserbazioa epe luzerako ziurta dadin (Ferrer \& 
Ferrando, 2013). Germoplasmako bankuak dira ex situ kontserbazio ekintza horien oinarria, dagoen landare biodibertsitatea germoplasman biltegiratuz (Bachetta et al., 2008). Germoplasma ugaltzeko eta epe luzera mantentzeko landarearen edozein zati izan daiteke baliagarria, eta haziak hoberenak biltzeko, garraiatzeko eta ugaltzeko (Ferrer \& Ferrando, 2013). Bestalde, zentro horietan hozidura protokoloak garatzen dira eta landare hazkuntzak burutzen dituzte, iraganeko landareen berreskurapen ekintzak hain zuzen, espezie mehatxatuen populazioak indartzeko lanak, adibidez (Gómez-Campo, 1985). Baina Germoplasma bankuetan biltzen den materialaren bideragarritasuna neurtzeko, ezinbestekoa da bideragarritasun probak egitea, kasurako Tetrazolio Testa, ernaltze saiakerak baino azkarragoak direnak, eta hazi kopuru gutxiago behar dutenak. Testuinguru honetan, Olarizuko Lorategi Botanikoak Germoplasma Bankua sortu zuen 2011. urtean, Euskal Autonomia Erkidegoko landare mehatxatuen ex situ kontserbazioa burutzeko (Agut, 2012), adibidez H. linifolium-a, Euskal Autonomi Erkidegoko Landare Mehatxatuen Katalogoan Galtzeko Arriskuan jotzen dena.

\section{Materialak eta metodoak}

\section{Haplophyllum linifolium (L.) G. Don fil.: Deskribapena:}

Haplophyllum generoa Rutaceae familian sailkatzen da. 70 espezie baino gehiago ditu genero honek, Mediterraneotik Liberiako ekialdera arte hedatzen direnak. Hala ere, Europan espezie horietatik zortzi baino ez daude eta, zehazki, Haplophyllum linifolium (L.) G. Don fil. Iberiar Penintsulako endemismoa da (Iñigo et al., 2002; Navarro et al., 2004).

26-28 cm-ko sastraka da. Zurtoinak tenteak, ile zurixkaz hornitua, ondulatuak eta leunak dira. Hostoak eliptikoak dira, batzuetan lantzeolatuak, sesilak edo motz peziolatuak, eskuarki beteak eta batzuetan trifidoak oinean bi segmentu txikirekin. Infloreszentzia 4-55 lorerekin, korinbo eran antolatuta. Obarioa ileduna da. Kapsula 4-6 mm-koa da, maiz itxura zimurtsuarekin, glandula mutur iledunengatik (Uribe-Echebarría et al., 2006; Morales, 2015) (1. irudia).

400-700 m-ko altueran bizi da, txapar, erromerodi, bide ertz nahiz artadi orletan. Oinarrizko eta nitrifikatutako substratuen zalea da (Aizpuru et al., 1999). Mendebaldeko eskualde mediterraneotik hedatzen da, endemikoa den eremutik hain zuzen ere. Iberiar Penintsulan, berriz, eite kontinentaleko klima duten eskualde mediterraneoetan ageri da, bereziki barneko depresio sedimentarioetan. Ebroko depresioan du bere ipar ekialdeko banaketa muga. Euskal Herrian bi populazio zeuden, Fontetxan eta Lasernan (Biasteri, Araba), eta bi horien artean beste bat, Miranda de Ebron (Burgos). Fontetxako populazioa, Arabako Foru Aldundiak 2013an baietsi zuen, BOPV/EHAA, 2011; Eusko Jaurlaritza/Gobierno Vasco, 2014) eta Miranda de Ebrokoa, ZEC Ebro Ibaiaren alboan kokaturik dago. Dena den, Lasernako populazioa desagertutzat jotzen da.

Babes sailkapenari dagokionez, Euskal Autonomia Erkidegoan desagertzeko arrisku larrienean dauden landareetakoa da. Lasernako populazioa desagertu izanak eta bigarren 

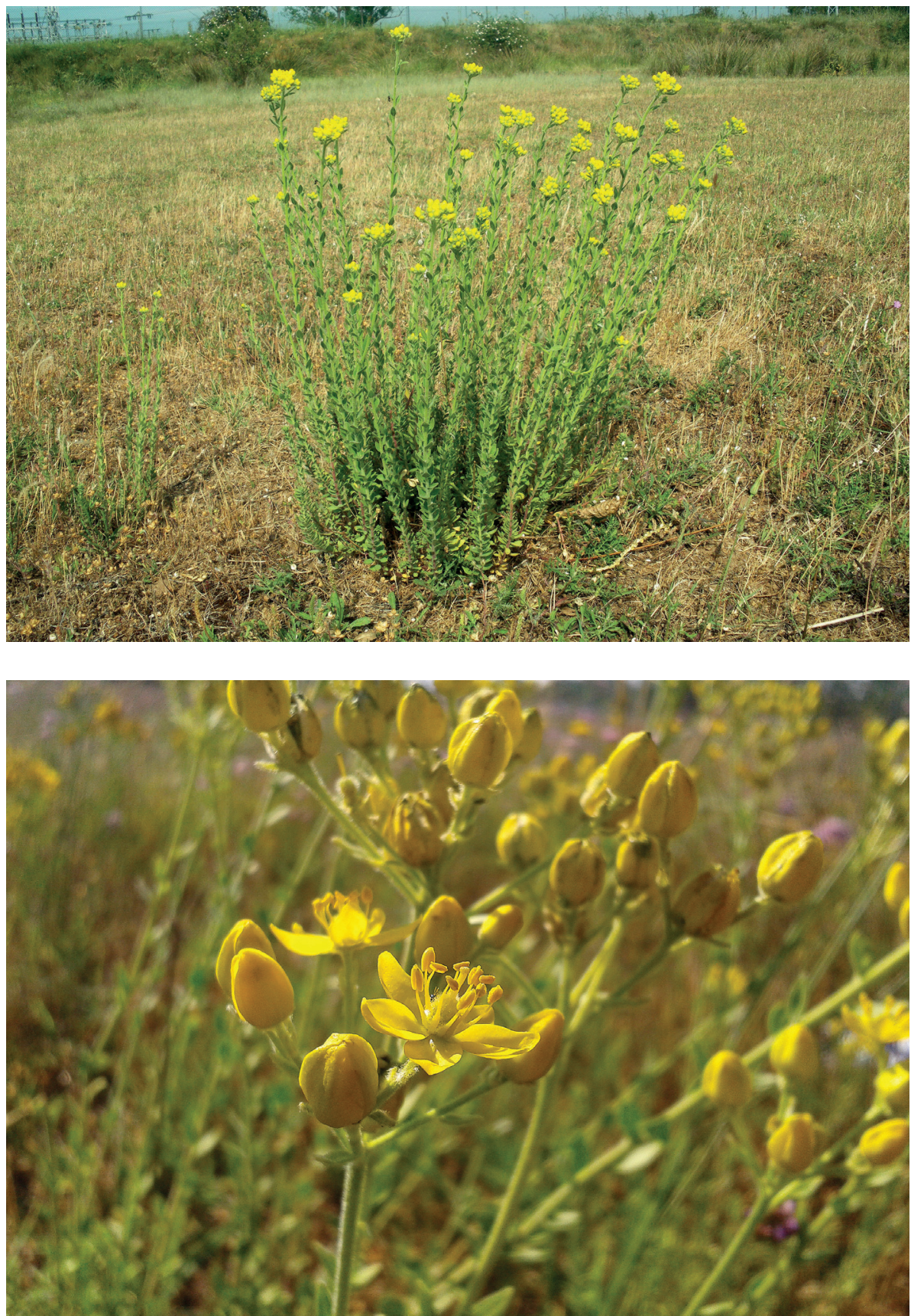

1. irudia.- H. linifolium Cabrianan (Miranda de Ebro, Burgos)

Fig. 1. - Haplophyllum linifolium in Cabriana (Miranda de Ebro, Burgos) 
populazioak jasandako atzerapenak agerian jartzen dute landare honen desagerpen arriskua. 1999an 6 landare erroldatu ziren $10 \mathrm{~m}^{2}$ ko area batean Fontetxako herrian. Ondoren, 2001 eta 2008an, 2 landare zenbatu ziren leku horretan. 2013. urtean, Olarizuko Lorategi Botanikotik erroldatu genuen populazio hori eta 2 indibiduo baino ez ziren aurkitu. Populazio txikia denez, inguruko jarduerek kalte egiten diote (egur metaketak, kotxeen aparkamendua, lurzoruan jardutea).

Testuinguru honetan, Arabako Foru Aldundiak Fontetxako populazioa hesitu egin zuen, hura babesteko asmoz. Ekintza horren ondorioz landare bat loratu zen eta fruitua eman zuen 2012an eta 2013an, eta lortutako haziak Olarizuko Lorategi Botanikoko Germoplasma Bankuan bildu ziren (Eusko Jaurlaritza/Gobierno Vasco, 2014). Arrazoi hauengatik, Euskadiko Flora Mehatxatuaren Zerrendan eta Euskadiko Zerrenda Gorrian (UICNko kategoriak) arrisku larrian bezala sailkatuta dago (CR) (BOPV/EHAA, 2011).

\section{Hazien deskribapena}

Ikerketa egiteko haziak, Euskadiko populaziotik hurbilen dagoen populazioan bildu ziren (Cabrianan, Miranda de Ebron), 15 aletatik, guztiak fruitu helduekin. Ondorioz, hazien karakterizazio morfologikoa egin zen (2. irudia) mikroskopio estereoskopiko apokromatiko Leica S8APO batekin.

\begin{tabular}{|ll|}
\hline Neurriak & $1,2 \times 1,8 \mathrm{~mm}$. \\
\hline Silueta & Giltzurruna, giltzurrun forma \\
\hline Ornamentazioa & Fobeolatua \\
\hline Kolorea & Marroia \\
\hline Sekzioa & Zirkularra, birbila \\
\hline Kotiledoi kopurua & Dikotiledoneoa \\
\hline Hazi kopurua fruitu bakoitzeko & 20-30 \\
\hline Uzta bildu zen banakoen kopuruen gainean & 15 \\
\hline Egoera fenologikoa & Fruitu helduak \\
\hline & $1 \mathrm{~mm}$ \\
\hline sooum & \\
\hline
\end{tabular}

2. irudia.- Haplophyllum linifolium-en hazien karakterizazio morfologikoa

Fig. 2. - Morphological characterisation of Haplophyllum linifolium seeds 
Erroldak

Populazio-erroldak zuzeneko estimazioarekin egin ziren, Euskaditik hurbilen dauden populazioetan (Cabrianan, Miranda de Ebron), eta Euskadiko bi populazioetan (Fontetxa eta Laserna).

Bideragarritasuna: Tetrazolio Testa

H. linifolium-en hazien enbrioia eta gainerako egiturak Tetrazolio soluzioari eraginpean jartzeko zeharkako mozketa bat egin zen lupa mikroskopikoa eta bisturia erabilita. Ondoren, 25 hazi tetrazolio \%1 disoluzio batean murgildu ziren, ilunpean, 24 orduz. Denbora hori igaro ondoren, hazien kolorea aztertu zen lupa mikroskopio estereoskopiko apokromatiko Leica S8APO batekin.

Hozidura testa

Espezie honetarako hozidura protokolorik ez dagoenez, informazioa bildu zen genero bereko eta antzeko ezaugarriak dituzten beste espezie batzuei buruz. Ruta genero espeziearen haziak ernetzea galarazten duten latentzia fisiologikoak izan ditzake, eta genero horretako espezieen ernetze tenperatura 20-25ㄷ da (Baskin \& Baskin, 2014).

Latentzia hori apurtzeko helburuarekin bi estratifikazio desberdin egin ziren, bata hotza eta bestea beroa, ernetzeari bietako zeinek laguntzen dion zehazteko. Saio bakoitzean 4 plaka erein ziren, eta bakoitzean 25 hazi. Bi estratifikazio baldintza eta kontrol bat ezarri ziren: estratifikazio beroa (P1, 20드.tan 60 egun), estratifikazio hotza (P2, 4 $\mathrm{C}$-tan 60 egun) eta kontrola (aurretratamendu gabea). Geroago ezarritako saiakera baldintzak hurrengo laurak izan ziren: $15^{\circ} \mathrm{C}, 20^{\circ} \mathrm{C}, 20 / 10^{\circ} \mathrm{C}$ eta $25^{\circ} \mathrm{C}, 12 / 12$ ordu argi/iluntasun fotoperiodokoak kasu guztietan. Baldintza horiek ezarri eta gero, haziak erein baino lehenago, sodio hipoklorito disoluzio bat erabiliz desinfektatu egin ziren (1\%, 20 minutu) (García et al., 2007; Bachetta et al., 2008; Álvarez et al., 2010). Ondoren, haziak lau aldiz garbitu ziren ur destilatuarekin, hipokloritoa guztiz kentzeko. Ernetzeko euskarria agarra izan zen \% 1eko kontzentrazioan (Bachetta et al., 2008; Agut \& Arrilucea, 2013). Agarra autoklabe batean esterilizatua (121ㄷ, 20 minutu). Ereitea, fluxu laminarreko kabinan egin zen, asepsia baldintzetan, Petri plaketan agarrarekin. Ondoren, plakak parafilmarekin zigilatu ziren. Ernetze zenbaketak astean hiru aldiz egin ziren. Agarretan hozitutako haziak erein ziren baso-albeolo erretiluetan, espeziearen habitat eta ekologia aldetik antzeko ezaugarriak dituen substratu nahaste batekin: substratu unibertsala (\%60), bermikulita (\%7) eta hondarra (\%33). Erretiluak ganbera kameretan mantendu ziren plantulen lehen garapenean. Azkenik, plantulak Olarizuko Lorategi Botanikoko negutegira eraman ziren.

Datu analisia

Hozidura probak amaitu eta gero, honako hozidura parametroak aztertu ziren: Hozidura Abiadura ( $\left.T_{50}\right)$, Hozidura Atzerapena $(R G)$, Batezbesteko Hozidura Denbora (GMT), Eguneroko Batezbesteko Hozidura (GMD), Hozidura Balorea (VG) eta Balore Pikoa (VP). 
Hozidura datuekin, analisi estatistikoa egin zen, baldintzen araberako hozidura ezberdintasunen ezaugarriak zehazteko. Datu horiek R software estatistikoarekin landu ziren (R Development Core Team, 2015).

Horretarako, prozedura Bernoulli saiakera modelo batera atxiki zen (Hosmer \& Lemeshow, 1989), zeinetan aldagai aleatorioa bi emaitzetara murriztu zen: arrakasta (hozitzea) edo porrota (ez hozitzea), non $p=$ arrakasta probabilitate eta bere bariantza $=p(1-p)$. Berriz, tenperatura modeloaren aldagai jarraiko bezala ezarri zen eta tratamendua aldagai kategoriko bezala.

\section{Emaitzak}

Erroldak

Alde batetik, Fontetxan (Araba) bi ale zenbatu ziren, Arabako Foru Aldundiak hesitutako partzelan. Populazio honen okupazioa $1 \mathrm{~m}^{2}$ baino txikiagoa da. Bestetik, Euskadiko beste populazioaren itzaltzea egiaztatu zen, Lasernan (Araba) zegoen karraskadia Ebro ibaiko terraza mahasti bat baita orain. Amaitzeko, hiru errolda egin ziren Miranda de Ebroko populazioan: loratu aurretik, loraketan eta fruitu ematerakoan. Bada, 22 ale zenbatu ziren (1. taula).

\begin{tabular}{|lccc|}
\hline Herria & Fontetxa & Laserna & Miranda de Ebro \\
\hline Koordenatuak UTM & 30TWN9732 & 30TWN4004 & 30TWN0227 \\
\hline Altuera $(\mathrm{m})$ & 480 & 400 & 470 \\
\hline Habitata & $\begin{array}{c}\text { Artederreta- } \\
\text { artadi orla. } \\
\text { Ebro ibaiko } \\
\text { terrazan }\end{array}$ & $\begin{array}{c}\text { Artederreta- } \\
\text { mahastia Ebro } \\
\text { ibaiko terrazan }\end{array}$ & $\begin{array}{c}\text { Larre lehorra } \\
\text { hondar-lur } \\
\text { gainean Ebro } \\
\text { ibaiko terrazan }\end{array}$ \\
\hline Banakoak & 2 & 0 & 22 \\
\hline
\end{tabular}

1. taula.- Haplophyllum linifolium espeziearen errolden emaitzak

Table 1. - Haplophyllum linifolium census results

Bideragarritasuna: Tetrazolio Testa

Ruta generorako eta Rutaceae familiarako Tetrazolio Testa egiteko protokolo estandarizaturik ez dagoenez, lortutako emaitzak Rubiaceae (Galium generoa) familiako haziekin konparatu ziren, antzeko ezaugarri morfologikoak dituztelako, eta horietarako protokoloak ezagunak direlako (ISTA 2003).

Tindaketa patroiak Galium generoan arruntak direnen antzekoak izan ziren. Hazi bideragarriak gorriz koloreztatu ziren, eta hazi ez-bideragarriak, berriz, kolore zuri-lilaz tindatu ziren. Honenbestez, bideragarritasun portzentajea \%64koa izan zen. 


\section{Hoziketa testa}

Hozidura portzentaje handienak ezarritako lau baldintzetan lortu ziren (15, 20, 20/10 eta $25 / 15^{\circ} \mathrm{C}, 12 / 12$ ordu argi/ilunpe), aldez aurreko estratifikazio hotza ( $4^{\circ} \mathrm{C}, 60$ egun) egin ondoren. Portzentaje horiek \%43 eta \%45 artekoak izan ziren (3. irudia). Lau baldintza horien hozidura ehunekoak konparatuta zaila da onuragarriena zein den zehaztea, hozidura parametroak oso antzekoak direlako. Alde batetik, baldintza guztietan Eguneroko Hoziduraren batezbestekoa berdina izan zen, eta baldintza guztietan haziak egun kopuru bera behar izan zuten hozidura lortzeko (hozidura atzerapen berbera). Bestetik, ernetzeko \%50 lortzeko, lau tratamenduen arteko aldeak minimoak dira, 20/10 $\mathrm{C}$-tan sei egun behar dituztelako eta ia bost egun beste tratamenduen kasuan. Ernetze kurbari erreparatuz, diferentzia adierazgarriak ikus daitezke $20^{\circ} \mathrm{C}$ eta $25 / 15^{\circ} \mathrm{C}$ tratamenduetan (batezbesteko tenperatura $20^{\circ} \mathrm{C}$ ), hau da, ernetze ehuneko maximoak lortzeko tenperatura horiek aldekoagoak dirudite tenperatura hotzak baino $\left(15^{\circ} \mathrm{C}\right.$ eta $\left.20 / 10^{\circ} \mathrm{C}\right)$ (4. irudia, 2. taula). Bestalde, analisi estatistikoek argi ezartzen dute aurretratamendua, kasu honetan estratifikazio hotza, hozidura protokoloa lortzeko parametroa esanguratsua dela, eta ez tenperatura (3. taula).

Hau guztia kontuan harturik, H.linifolium-en hozidura protokoloak estratifikazio hotz bat behar du aurretratamendu bezala, tenperatura epelekin jarraituta. Halaber, analisi estatistikoek berresten dute estratifikazio hotza egin beharra hoziduran arrakasta lortzeko aurretratamendu bezala.

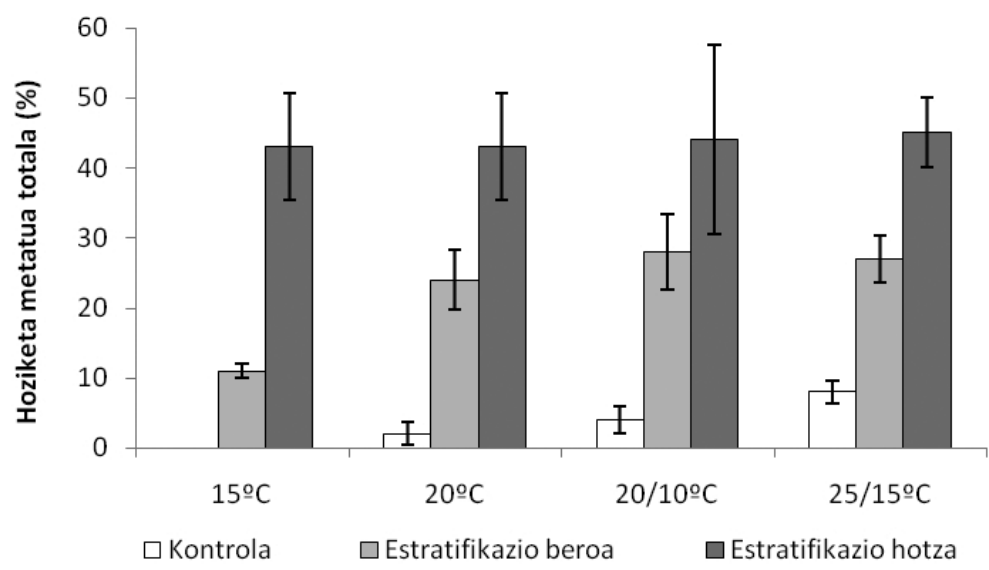

3. irudia. - Hozidura metatua guztira ehunekotan

Fig. 3. - Total cummulative germination percentage 


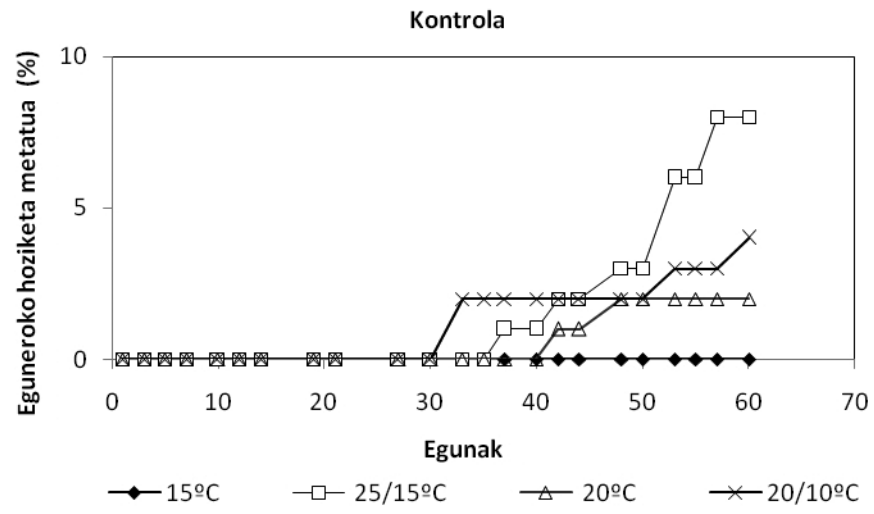

Estratifikazio hotza

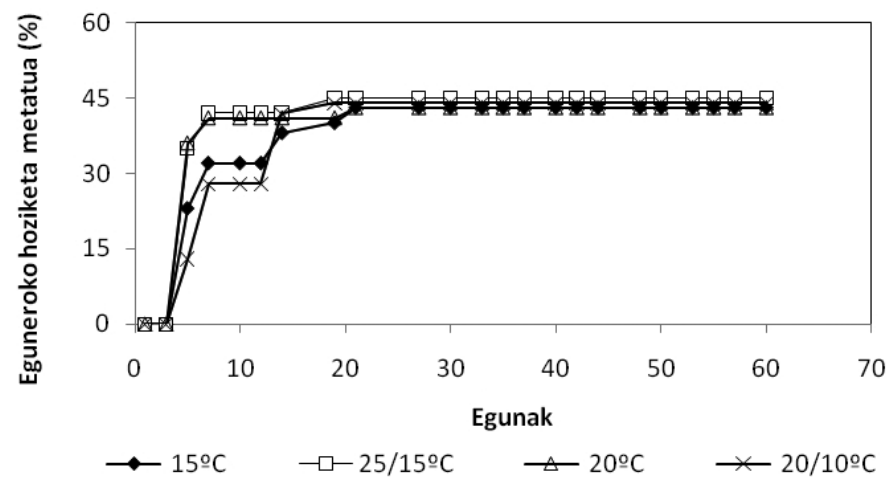

Estratifikazio beroa

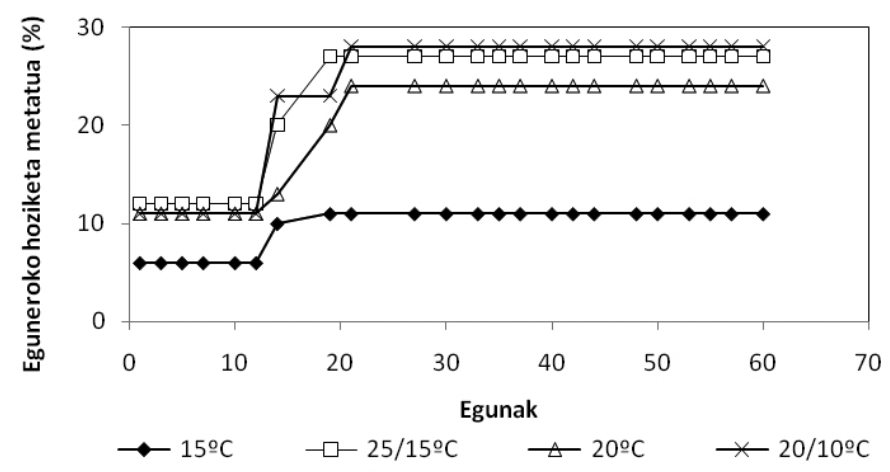

4. irudia. - Eguneroko hozidura ehuneko metatua tratamendu bakoitzerako Fig. 4. - Daily germination percentage for each treatment 


\begin{tabular}{|l|c|c|c|c|c|c|c|c|}
\hline Aurretratamendua & $\begin{array}{c}\mathrm{T}^{\mathrm{T}} \\
\left({ }^{\circ} \mathrm{C}\right)\end{array}$ & $\begin{array}{c}\text { T50 } \\
(\text { Egunak })\end{array}$ & $\begin{array}{c}\text { GMT } \\
(\text { Egunak })\end{array}$ & VP & $\begin{array}{c}\text { GMD } \\
(\%)\end{array}$ & RG & VG & $\begin{array}{c}\text { HOZIKETA } \pm \\
\text { E.S }(\%)\end{array}$ \\
\hline P1 & 15 & - & 9.75 & 0.2 & 0.18 & - & 0,036 & $11 \pm 1$ \\
Estratifikazio & 20 & 13 & 13.89 & - & 0.41 & - & - & $24 \pm 4,3204$ \\
beroa & $20 / 10$ & 12.5 & 11.35 & 0.5 & 0.46 & - & 0,23 & $28 \pm 5,416$ \\
$\left(20^{\circ} \mathrm{C}\right)$ & $25 / 15$ & 12.37 & 13.33 & - & 0.45 & - & - & $27 \pm 3,4156$ \\
\hline P2 & 15 & 4.87 & 12.73 & 6 & 0.72 & 5 & 4,32 & $43 \pm 7,5498$ \\
Estratifikazio & 20 & 4.19 & 7.41 & 6 & 0.72 & 5 & 4,32 & $43 \pm 7,5498$ \\
hotza & $20 / 10$ & 6.2 & 12.75 & 1.87 & 0.73 & 5 & 1,36 & $45 \pm 13,564$ \\
$\left(4^{\circ} \mathrm{C}\right)$ & $25 / 15$ & 4.29 & 7.84 & 5.83 & 0.75 & 5 & 4,36 & $44 \pm 5$ \\
\hline & 15 & - & 0 & - & 0 & 0 & - & $0 \pm 0$ \\
Kontrola & 20 & 42 & 36 & 0.021 & 0.03 & 42 & 0,0063 & $2 \pm 1,6329$ \\
& $20 / 10$ & 33 & 11.12 & 0.067 & 0.07 & 33 & 0,0047 & $4 \pm 2$ \\
& $25 / 15$ & 51 & 50.5 & 0.035 & 0.13 & 37 & 0,0045 & $8 \pm 1,6329$ \\
\hline
\end{tabular}

2. taula.- Lortutako hoziketa ehunekoak eta hoziketa parametroak tratamendu bakoitzerako

Table 2. - Percentages and germinative parameters obtained for each treatment.

\begin{tabular}{|c|c|c|c|c|}
\hline & $\begin{array}{l}\text { Parametro } \\
\text { estimatuak }\end{array}$ & $\begin{array}{l}\text { Akats } \\
\text { estandar }\end{array}$ & z Balorea & $\operatorname{Pr}(>|z|)$ \\
\hline$\beta 0$ & $-1,014075$ & 1,185031 & $-0,856$ & 0,392 \\
\hline$\beta 1$ (pret) & $-0,552942$ & 0,088075 & $-6,278$ & $3,43 e-10^{* * *}$ \\
\hline$\beta 2$ (temp) & 0,667411 & 1,773109 & 0,376 & 0,707 \\
\hline$\beta 3($ temp^ 2$)$ & $-0,137251$ & 0,777257 & $-0,177$ & 0,860 \\
\hline$\beta 4($ temp^3) & 0,008901 & 0,102702 & 0,087 & 0,931 \\
\hline \multicolumn{5}{|c|}{ LnOdds $=\beta 0+\beta 1^{*}$ pret $+\beta 2^{*}$ temp $+\beta 3^{*}$ temp $2+\beta 4^{*}$ temp3 } \\
\hline \multicolumn{5}{|c|}{ LnOdds $=-1,014075-0,552942 *$ pret $+0,667411^{*}$ temp $-0,137251^{*}$ temp2 $+0,008901 *$ temp3 } \\
\hline
\end{tabular}

***Signifikantzia maila 0,001

3. taula.-Erregresio Binomial Logistikoa Haplophyllum linifolium espeziean

Table 3. - Logistic Binomial Regression for Haplophyllum linifolium 


\section{Eztabaida}

Espezie mehatxatuen kontserbazioa Lorategi Botanikoetan eta Germoplasma Bankuetan funtsezkoa da, zaharberritzeko edota populazioen berreskuratze planak egiteko (Godefroid et al., 2011). Germoplasma Bankuetan, utzitako materiala balio handikoa da eta, horregatik, material honen ugaltze kalitatea ebaluatzea oinarrizkoa da, hazien bideragarritasuna denborarekin murriztu egiten delako biltegiratze baldintzetan (Probert et al., 2009). Horretarako, aukera hoberena da ernetze probak egitea behin espezie bakoitzerako baldintza zehatzak zehaztu ondoren. Proba horien eragozpen nagusiena zera da, bai denboran bai baliabideetan oso garestiak direla. Gainera, ugaltze materiala -kasu honetan haziak- kantitate handietan erabili behar da. Ondorioz, bideragarritasun probak, ernetze probekin konparatuz, aukera ekonomikoagoa eta azkarragoa dira, materialaren kalitatea zehazten duen aktibitate biologikoa islatzen dutelako.

Hala ere, ernetze saiakerak bezala, bideragarritasun probek optimizazioa eskatzen dute espezie bakoitzerako. Ikerketa honetan Haplophyllum linifolium-en hozidura protokoloak lortu dira, eta hazien bideragarritasuna neurtzeko Tetrazolio proba egin da. Emaitzak balio handikoak dira Euskal Herrian kontserbatu beharra duen landare honen kasuan, eta protokolo horien garapena nahitaezkoa da, ez baitago inolako informaziorik.

Lortutako hozidura ehunekoak handiak izan ziren, \%45, estratifikazio hotza egin ondoren. Ehuneko horiek gorenak izan ziren beste autore batzuek lortutakoen aldean (Genmedoc, 2014); izan ere, azken horiek \%1 baino ez zuten lortu, 20/10C eta 12 ordu argi/ilunpe baldintzetan. Emaitza horiek eta egindako analisi estatistikoak (3. taula) agerian uzten dute estratifikazio hotza egin beharra dagoela aurretratamendu bezala. Espeziaren ekologia aztertuta, estratifikazio hotza Haplophyllum-en haziak aktibatzeko seinalea da, ernetzea lortzeko negua igaro ondoren, udaberriko tenperaturei eta euriei begira.

\section{Bibliografia}

- Agut, A. 2012. El Banco de Germoplasma Vegetal del Jardín Botánico de Olárizu. Biogaia 6-7.

- Agut, A., González de Arrilucea, G. 2013. Desarrollo de mejoras e innovación en el protocolo de ensayos de germinación de semillas del Banco de Germoplasma del Jardín Botánico de Olárizu. Banco de Germoplasma Vegetal de Jardín Botánico de Olárizu, Ayuntamiento de Vitoria-Gasteiz.

- Aizpuru, I., Aseginolaza, C., Uribe-Echebarría, P.M., Urrutia, P., Zorrakin, I. 1999. Claves ilustradas de la flora del País Vasco y territorios limítrofes. Servicio Central de Publicaciones del Gobierno Vasco.Vitoria-Gasteiz.

- Álvarez, M., Silva, J.J., Viera, Y., Troyo, E. 2010. Desinfección de semillas maduras de maíz (Zea mays (L.) para su establecimiento in vitro y caracterización de hongos contaminantes. Rev. Electróncia Granma Cienc. 14 (1): 1-5. 
- Bachetta, G.., Bueno, A., Fenu, G.., Jimenez, B., Mattana, E., Piotto, B., Virevaire, M. 2008. Conservación ex situ de plantas silvestres. La Caixa. Principado de Asturias.

- Bañares, A., Blanca, G., Güemes, J., Moreno, J.C., Ortiz, S. 2010. Atlas y Libro Rojo de la Flora Vascular Amenazada de España. Dirección General de Medio Natural y Política Forestal. Ministerio de Medio Ambiente, y Medio Rural y Marino. Sociedad Española de Biología de la Conservación de Plantas. Madrid.

- Baskin, J.M., Baskin, C.C. 2014. Seeds. Ecology, Biogeography, and Evolution of Dormancy and Germination. Elsevier.

- BOPV/EHAA. 2011. Orden 10 de Enero de 2011, de la Consejera de Medio Ambiente, Planificación Territorial, Agricultura y Pesca, por la que se modifica el Catálogo Vasco de Especies Amenazadas de la Fauna y Flora Silvestre y Marina y se aprueba el texto único. Departamento de Medio Ambiente, Planificación Territorial, Agricultura y Pesca del Gobierno Vasco. Vitoria-Gasteiz.

- Eusko Jaurlaritza/ Gobierno Vasco 2014. Designación de la Zona Especial de Conservación ES2110008 Río Ebro/Ebro Ibaia. Documento de información ecológica y objetivos de conservación.

- Ferrer, PP., Ferrando, I., Gago, C., Laguna, E. 2013. Manual para la conservación de germoplasma y el cultivo de la flora valenciana amenazada. Colección Manuales Técnicos Biodiverisdad, 3.Consellería d'infraestructures, Territori i Medi Ambient. Generalitat Valenciana. Valencia.

- García, Y., Freire, M., Tejeda, M., Reyes, M. 2007. Germinación in vitro de semillas de Dendrocalamus strictus (Rosb.) Nees. Biotecnol. Vegetal 7(1): 41-44.

- Genmedoc. Un résau interrégional de banques de semences de la méditerranée. 2014. Haplophyllum linifolium (L.) G. Don fil., fiche germination. Proyecto Genmedoc.

- Godefroid, S., Rivière,S., Waldren, N., Boretos, R., Vanderborght, T. 2011. To what extent are threatened European plant species conserved in seed banks? Biol. conserv. 144 (5): 1494-1498.

- Gómez-Campo, C. 1985. Plant conservation in the mediterranean area. W. Junk Publishers. Dordrecht. Holland.

- Hosmer, D.W., Lemeshow, S. 1989. Applied Logistic Regression. John Wiley \& Sons. Nueva York.

- Iñigo, A., Pala-Paúl, J., Pérez-Alonso, M.J., Velasco-Negueruela, A. 2002. A Essential Oil composition from the aerial parts of Haplophyllum linifolium (L.) G. Don fil. Botanica Complutensis 26: 79-83.

- ISTA. 2003. Working Sheets on Tetrazolium Testing. Agricultural, Vegetable and Horticultural Species. International Seed Assosiation.

- Morales, R. 2015. Haplophyllum A. Juss. En: Flora Iberica IX. Castroviejo, S., Aedo, C., Laínz, M., Muñoz Garmendia, F., Nieto Feliner, G., Paiva, J. \& Benedí, C. (Ed.): 134-138. Real Jardín Botánico, CSIC. Madrid.

- Navarro, F.B., Suárez-Santiago, V.N., Blanca G. 2004. A New Species of Haplophyllum A. Juss. (Rutaceae) from the Iberian Peninsula: Evidence from Morphological, Karyological and Molecular Analyses. Annals of Botany 94(4): 571-582. 
- Phartyal, S.S., Thapliyal, R.C., Koedman, N., Godefroid, S. 2002. Ex situ conservation of rare and valuable forest tree species through seed-gene bank. Current Science 83: 1351-1357.

- Probert, R.J., Daws, M.I. y Hat, R.F. 2009. Ecological correlates of ex situ seed longevity: a comparative study on 195 species. Ann. Bot. 104 (1): 57-69.

- R Development Core Team. 2015. R: A language and environment for statistical computing. R Foundation for Statistical Computing. Viena.

- Uribe-Echebarría, P.M., Zorrakin, I., Campos. J.A., Dominguez, A. 2006. Euskal Autonomia Erkidegoko flora baskular mehatxatua. Eusko Jaurlaritzaren Argitalpen Zerbitzu Nagusia. Departamento de Medio Ambiente y Ordenación del Territorio del Gobierno Vasco. VitoriaGasteiz. 